Military Technical College Kobry El-Kobbah, Cairo, Egypt

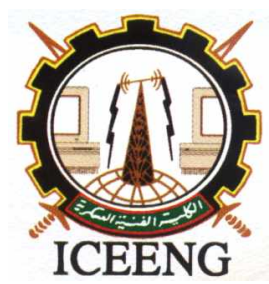

\author{
$6^{\text {th }}$ International Conference \\ on Electrical Engineering \\ ICEENG 2008
}

\title{
Power consumption pattern determination method to optimize electrical distribution system
}

\author{
By \\ L.C.Kho* C.J.Chai* $\quad$ S.S.Ngu* ${ }^{*} \quad$ Leslie K.P. Chai** Alvin K.L. Lim**
}

\section{Abstract:}

Due to the rapid growth of the population in Kuching area lately, the power consumption pattern, diversity factor, after diversity maximum demand (ADMD) and load factor become the critical issues to be studied and revised in details in order to improve the system planning and reduce the capital expenditure. To achieve this objective, method to determine the power consumption pattern for different class of consumers in Kuching area is proposed in this paper. The power consumption data for consumers were recorded using a specialized meters installed at their premises. The sampling theory is present in this paper to determine the sample size and the number of meters needed to be installed. The raw data obtained from these meters were analyzed to obtain the pattern of power consumption for different classes of consumers in Kuching to determine the load factor and diversity factor. Besides, the value of ADMD was calculated to verify the optimal amount of load to be supplied to the housing development area, resulting in better planning and leading to a more efficient usage of resources to generate electricity.

\section{Keywords:}

Power consumption pattern, load factor, diversity factor, after diversity maximum demand and peak load

* Faculty of Engineering, Universiti Malaysia Sarawak, Sarawak, Malaysia

** Syarikat SESCO Berhad, Sarawak, Malaysia 


\section{Introduction:}

Due to increasing population and depletion of fossil fuel, impulse to increasing demands of power. Nowadays, electricity is supplied to different types of the consumers. In this study, power consumption pattern, diversity factor and load factor for selected types of consumers as shown in table 1 will be investigated. With more and more electricity consumers, the power consumption pattern, diversity factor, load factor, diversity maximum demand and reduce capital expenditure are critical issues to be fully developed. The objectives of studying on power consumption pattern, load characteristic and consumer behavior will assist us in improving system operation \& maintenance efficiency, improving system planning efficiency and reducing capital expenditure.

Table (1): Types of consumers that will investigate

\begin{tabular}{|l|c|}
\hline No. & Type of consumer \\
\hline 1. & Domestic \\
\hline 2. & Commercial \\
\hline
\end{tabular}

Several factors that were considered in this paper which will determine the power consumption pattern are listed below.

- Consumer

- Difference types of consumers use electricity differently depending on their behavior.

- Time

- The usage of electricity varies with time depending on human and economic activities.

Sarawak Energy Berhad, through its subsidiary, Syarikat SESCO Berhad is responsible for the generation, transmission and distribution of electricity in the state of Sarawak. The total number of power consumers has grown from 260,214 in 1996 to 414,767 in 2005 , representing a growth rate within 10 years of $59.39 \%$. Consequently, the total electricity sold in 1996 was $1.94 \mathrm{TWH}$, increasing to $3.94 \mathrm{TWH}$ in 2005 . This represents a growth rate within 10 years of $103.09 \%$. Due to the dramatic increase in electricity consumption as shown in figure 1 and 2, the power consumption pattern, consumer behavior and load characteristics become critical issues to be investigated so that the network can be planned, designed and operated efficiently to meet the increasing yearly demand. 


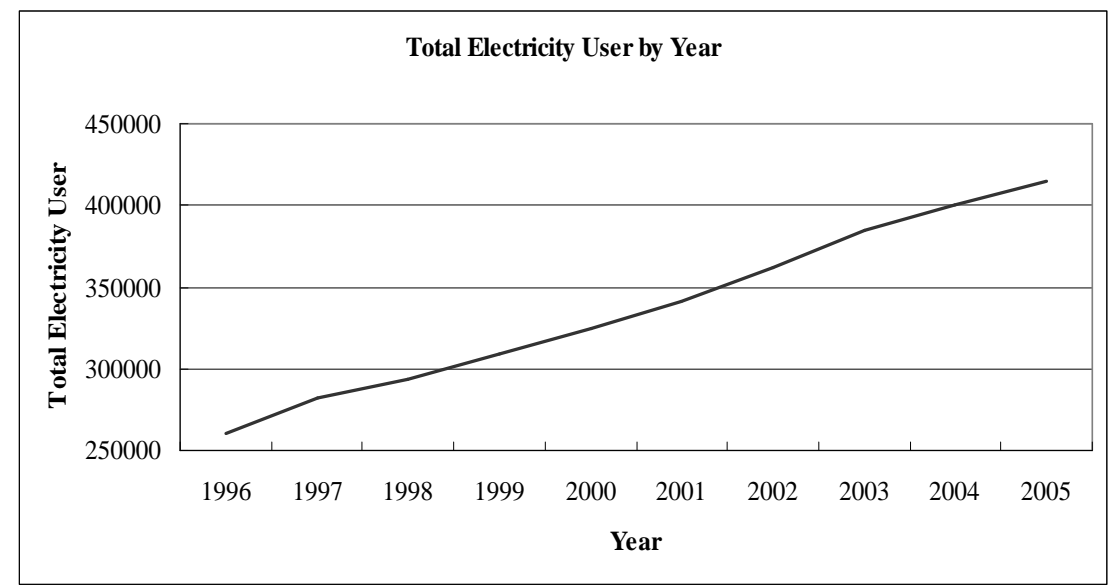

Figure (1): Total electricity consumer in Sarawak from year 1996 to 2005

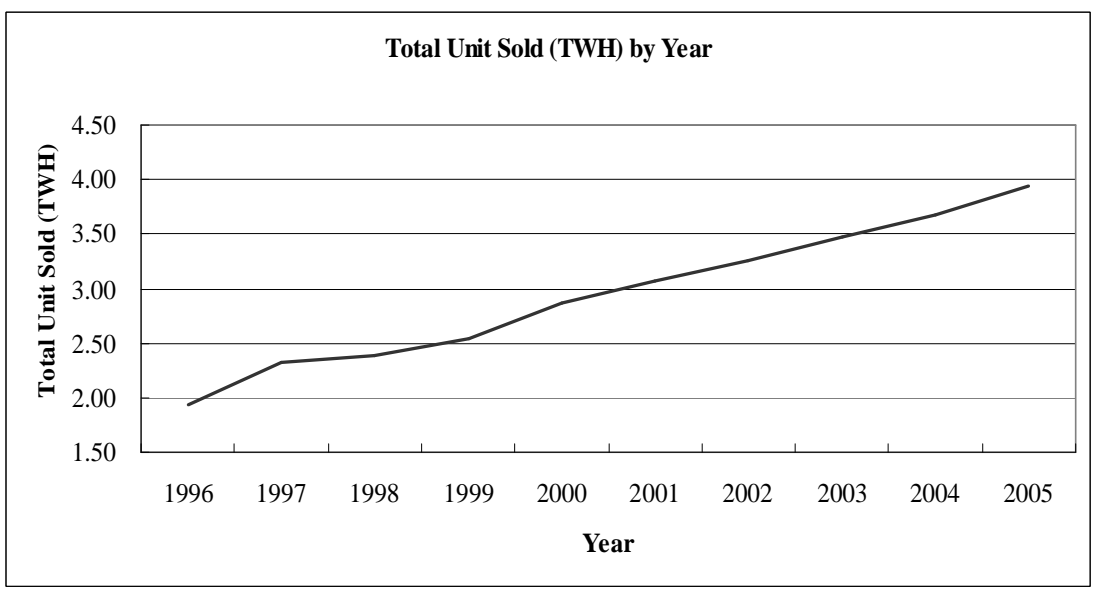

Figure (2): Total unit sold (TWH) by SESCO from year 1996 to 2005

The power consumption pattern for domestic and commercial consumers will be investigated in this paper. The power consumption pattern of industrial customers was not studied in this paper. Different types of consumers have different value of factors and method to find out these factors will show this paper.

2. Procedure of power consumption pattern, consumer behavior and load characteristics research:

This paper investigates and analyzes two types of consumers which are domestic and commercial. Special meters were installed to determine power consumption pattern and load characteristics for each type of consumers. From the power consumption pattern, diversity factor, load factor, after diversity maximum demand will be determined. 
Analyzing the data obtained from installation will help improve the system planning, operation and maintenance efficiency, capital expenditure will be reduced. The whole study procedure is shown in figure 3 .

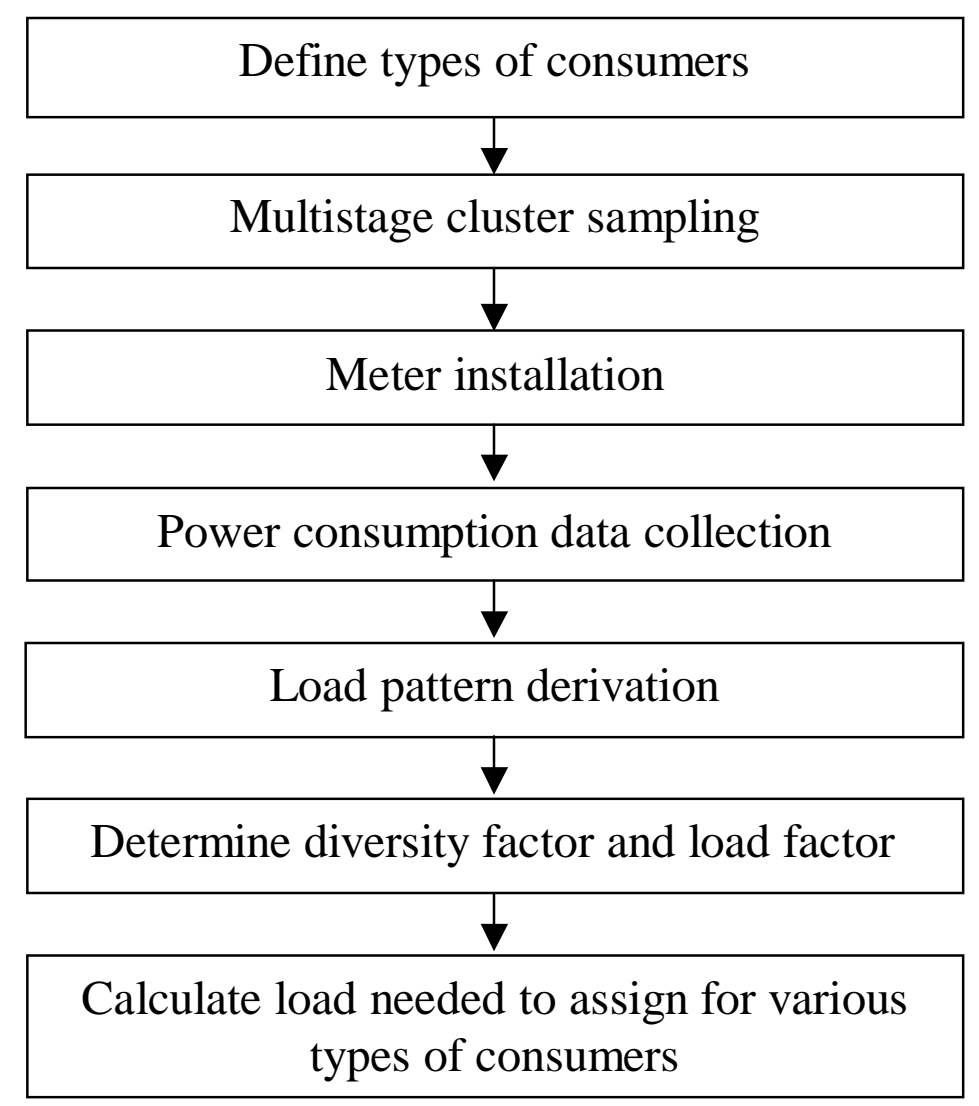

Figure (3): Study procedures on power consumption pattern consumer behavior and load characteristics

\section{Sample design:}

Due to the large number of consumers, it is impossible to do sampling that covered all the population in Kuching. To make sure that reliable data is collected from a representative sample size, it is necessary to use the sampling theory to select a proper size of consumer to install meter [1]. 
Table (2): Sample size for various types of consumers

\begin{tabular}{|l|c|}
\hline Type of consumer & Sample size \\
\hline Domestic & 190 \\
\hline Commercial & 36 \\
\hline
\end{tabular}

The sampling theory is applied based on the total number of consumers classified under the two types of consumers within the selected area. In this paper, multistage cluster sampling is used to design the sample size. Two types of consumers as shown in table 1 were selected. To design the proper sample size, population proportion $\mathrm{p}$ and size of the population $\mathrm{N}$ of total unit for each type of consumers is needed. The sample size, $\mathrm{S}$ with $90 \%$ confidence level [2] for each type of the consumers is determined by equations (1) and (2) [3]. Table 2 shows the minimum sampling size of domestic and commercial consumers.

$$
\begin{aligned}
& S=\frac{S_{0}}{1+\frac{S_{0}-1}{N}} \\
& S_{0}=\frac{z^{2} p q}{e^{2}}
\end{aligned}
$$

\section{Data collection and analysis of power consumption pattern:}

Collecting data are the initial requirement, which complement to the success of a project. To derive the power consumption pattern, meter were installed at number of consumers according to sample design. Meters are use to measure and record the kilowatt hour (KWH) and kilovolt-ampere-hour (KVAH) at the interval of 15 minutes over 2 months period. From the data that were collected from meter, the daily power consumption pattern for each type of the consumers can be derived. This power consumption pattern will then be used to determine several other factors such as load factor and diversity factor. When the diversity factor for different types of consumers is determined, the value of after diversity maximum demand (ADMD) can be calculated. Using the ADMD, the optimal amount of load to be supplied to any area of development can be determined.

The data collected from the installation on the power consumption pattern of the two types of consumers is represented graphically herewith. 
Through the installation that was done, the power consumption pattern can be identified. Figure 4 shows the comparison of power consumption pattern by the two different types of consumers, which are domestic and commercial consumers. For domestic consumer, electrical load will be high during night time when people stayed at home and electric usage will be lower during daytime when people left their home for work. Power consumption pattern for commercial consumer is different compared to the domestic consumer, electrical load will be high during daytime when people were at work. Commercial consumer consumes electricity much more than domestic consumer. Peak load and time when the peak load occurs for domestic and commercial consumer can be determined as shown in table 3 .

Table (3): Peak load and time when the peak load occurs for various types of consumers

\begin{tabular}{|l|c|c|}
\hline Consumer & Time & Peak Load (KW) \\
\hline Domestic & $11.00 \mathrm{p} . \mathrm{m}$ & 1.34 \\
\hline Commercial & $3.30 \mathrm{p} . \mathrm{m}$ & 5.42 \\
\hline
\end{tabular}

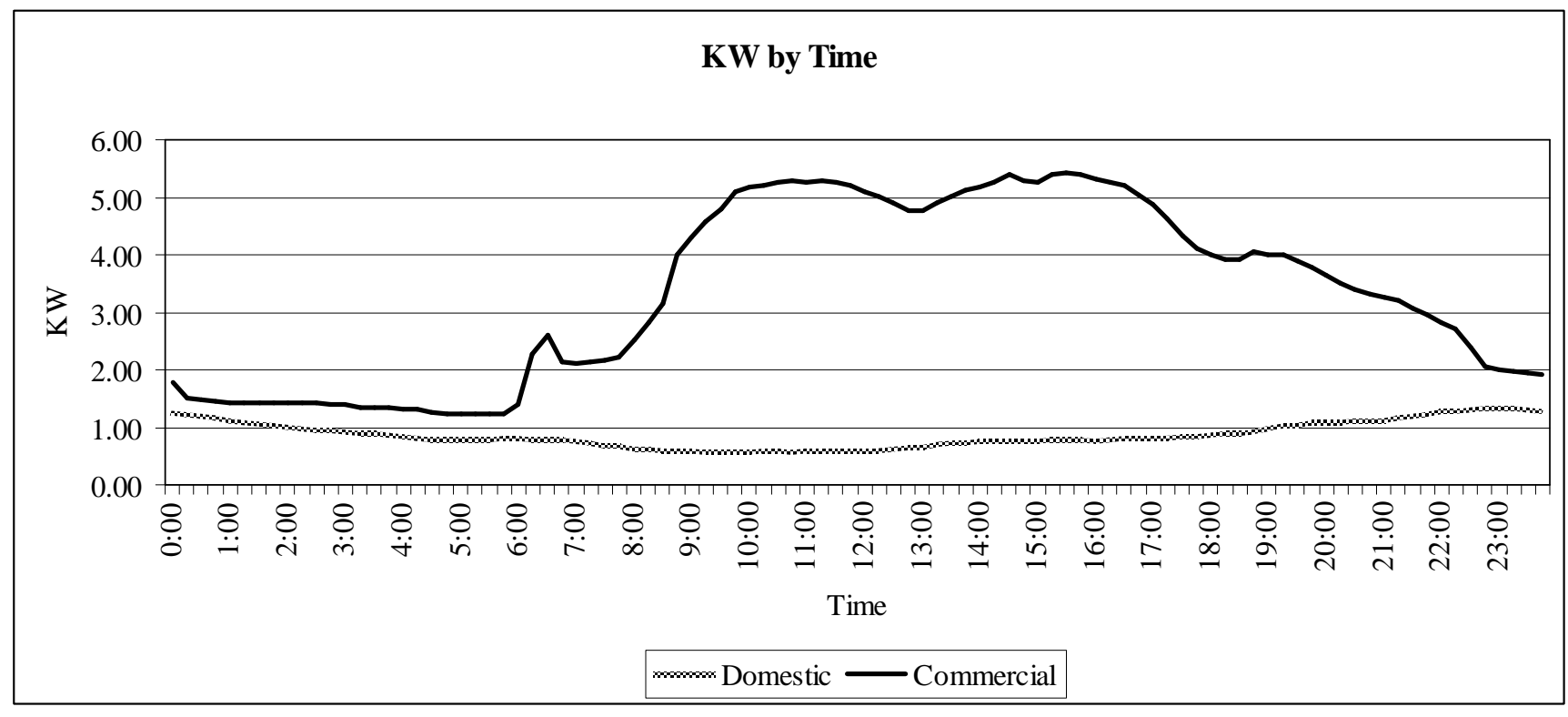

Figure (4): Comparison power consumption pattern for domestic and commercial consumer 


\section{Method to determine and load factor, diversity factor and after demand maximum} demand:

To improve system operation \& maintenance and system planning efficiency, load factor and diversity factor need to determine. Load factor and diversity factor can be calculated through the data that obtain and power consumption pattern that derive for various types of the consumers.

Load factor is the best way to determine how much the energy is wasted. To determine the load factor, average demand and maximum demand is needed [4]. The load factor for each type of the consumers will be determined by the equation 3 .

Load Factor, $\mathrm{LF}=\frac{\text { Average demand }}{\text { Maximum demand }}$

Diversity factor among the consumers is use to meet the utility and demand [5]. To determine the diversity factor, the maximum noncoincident demand of a group consumers and maximum diversified demand of the group is needed [6]. The diversity factor for each type of the consumers will be determined by the equation 4 .

Diversity Factor, $\mathrm{DF}=\frac{\text { Maximum noncoincident demand }}{\text { Maximum diversifie d demand }}$

The maximum demand of each consumer of a group of homogeneous after all diversity has been considered is call after diversity maximum demand (ADMD). The after diversity maximum demand for each type of the consumers will be determined by the equation 5 [7].

$\operatorname{ADMD}_{(\mathrm{N})}=\frac{\text { Maximum recorded load for } \mathrm{N} \text { customers }}{\mathrm{N}} \mathrm{KVA}$

Where $\mathrm{N}$ is the number of consumers connected.

After $\operatorname{ADMD}_{(\mathrm{N})}$ is determined, $\mathrm{ADMD}_{(\mathrm{inf})}$ can be determined by equation 6.

$$
\operatorname{ADMD}_{(\mathrm{inf})}=\frac{\mathrm{ADMD}_{(\mathrm{N})}}{\mathrm{DF}_{(\mathrm{N})}}
$$


Data on total load demand for each type of consumers can be getting from the power consumption pattern that derived. The calculation of the total load demand for the purpose of sizing the transformer and determining the cable size is needed.

The load factor for various types of consumers is show in table 4. Load factor gives an indication of how well the utility's facilities are being utilized and how much the energy is wasted. The optimal load factor would be 1 . When the load factor is high, it means the load is runnning near the peak demand.

Table (4): Load Factor for various types of consumers

\begin{tabular}{|l|c|}
\hline Consumer & Load Factor \\
\hline Domestic & 0.66 \\
\hline Commercial & 0.62 \\
\hline
\end{tabular}

The diversity factor and after diversity maximum demand for various types of consumers is show in table 5. By knowing the value of after diversity maximum demand, total load needed to assign to the domestic and commercial consumers can be determined.

Table (5): Diversity factor and after diversity, maximum demand for various types of consumers

\begin{tabular}{|l|c|c|}
\hline Consumer & Diversity Factor & After Diversity Maximum Demand (KVA) \\
\hline Domestic & 1.19 & 1.26 \\
\hline Commercial & 1.11 & 5.72 \\
\hline
\end{tabular}

\section{Conclusions:}

Determination of consumer load characteristics is an important step to improve system operation, maintenance and planning efficiency. From power consumption pattern, load characteristic for various types of consumers can be determined. In this paper, sampling theory is used to design a proper sample size. Power consumption pattern for each type of consumers will be derived and important factors such as load factor, diversity factor and after diversity maximum demand are determined. By using the value of after diversity maximum demand, the total load needed to any area of development can be determined. By this study, the load characteristics can be determined to support utility operation and planning more effectively, capital expenditure can be reduced. 


\section{Acknowledgement:}

This work was supported by the Universiti Malaysia Sarawak (UNIMAS) of Malaysia. The author would like to express sincere appreciation and gratitude to all the lecturers and students who have provided tremendous assistance throughout the project.

\section{References:}

[1] Chen, C.S ET. AL. "Determination of consumer load characteristics by load survey system at Taipower" IEEE Transactions on Power Delivery (1996) Page(s):1430 1436.

[2] Robert Johnson and Patricia Kuby, "Just the essentials of elementary statistics", Duxbury - Thompson Learning, USA (2005).

[3] Luck, DJ Taylor, W.G \& Robin "Marketing Research Eaglewood", Prentice Hall, 1987.

[4] Anthony J. Pansini "Guide to Electrical Power Distribution Systems", Prentice Hall. (1992).

[5] Sargent, A ET. AL. "Estimation of diversity and kWHR-to-peak-kW factors from load research data" IEEE Transactions on Power System (1994) Page(s):1450 1456.

[6] William H.Kersting “ Distribution System Modeling and Analysis”, CRC Press LLC (2002).

[7] Anon. "Distribution Planning Manual”, SESCO. (2002).

\section{Nomenclatures:}

N ... Size of the population

P ... Population proportion

q $\ldots \quad(1-p)$

e ... Proportion of sampling error

z ... Standard score corresponding to a given confidence level

S ... Sample size 